\title{
Entropi ve MABAC Yöntemleri ile Personel Seçimi
}

\author{
DOI: 10.26466/opus.580456
}

*

\begin{abstract}
Alptekin Ulutaș
*Dr. Öğr. Üyesi, Sivas Cumhuriyet Üniversitesi, İ.İ.B. Fakültesi, UTL Bölümü, Sivas / Türkiye E-Posta: aulutas@cumhuriyet.edu.tr

ORCID: 0000-0002-8130-1301
\end{abstract}

\section{Öz}

Kalifiye personelin iş ile ilgili bilgiye sahip olması, iş deneyiminin olması ve işe yatkınlı̆̆ vb. yetenekleri işletmelerin başarısında etkin bir rol oynamaktadır. Bu sebepten dolayı kalifiye personel istihdamının yapılması mühim bir süreç olarak görülmektedir. Personel değerlendirmesinde amaç; açılan pozisyona başvuran adaylan uygun kriterler göz önünde bulundurularak adayların performansların ölçmek ve pozisyona en uygun adayı belirlemektir. Personel değerlendirmesinde ve seçiminde birden fazla kriter göz önünde bulundurulduğu için ÇKKV (çok kriterli karar verme) yöntemlerinden faydalanulabilir. Bu çalışmada Entropi ve MABAC yöntemlerinden oluşan bir ÇKKV modeli önerilmiştir. Bu çalı̧̧ma iki açıdan literatüre katkı sunmayı hedeflemektedir. Illk olarak MABAC yöntemi ile ilgili Türkçe literatürde az sayıda yayın bulunmaktadır. Ayrica Entropi ve MABAC yöntemlerinin birlikte kullanımı ile ilgili makale sayısı literatürde az sayıdadır. Bu çalışma yukarıdaki araştırma boşlukların doldurarak literatüre katkı sunmayı amaçlamaktadır. Çalışmada önerilen ÇKKV modeli bir mobilya atölyesi için en uygun pazarlama yöneticisi belirlenmesinde kullanılmıştır. Gelecek çalışmalar MABAC yöntemini farklı ÇKKV problemleri için kullanabilirler.

Anahtar Kelimeler: Entropi, MABAC, Personel Seçimi. 


\title{
Personnel Selection with Entropy and MABAC Methods
}

\begin{abstract}
Capabilities of qualified personnel, such as having knowledge of the job, job experience and tendency to job etc. play an active role in the success of businesses. Therefore, the employment of qualified personnel is seen as an important process. The aim of the personnel evaluation is to measure the performance of the candidates applying to the opened position while considering the appropriate criteria and to determine the most suitable candidate for the position. Since multiple criteria are taken into consideration in the selection and evaluation of personnel, MCDM (multi-criteria decision-making) methods can be utilized. In this study, an MCDM model consisting of Entropy and MABAC (multi-attributive border approximation area comparison) methods was proposed. This study aims to contribute to the literature from two sides. Firstly, there are few publications in the Turkish literature about the MABAC method. Additionally, the number of articles related to the use of Entropy and MABAC methods together in the literature is few. This study aims to contribute to the literature by filling the gaps above-mentioned. The MCDM model proposed in the study was used to determine the most suitable marketing manager for a furniture workshop. Future studies may use the MABAC method for different MCDM problems.
\end{abstract}

Keywords: Entropy, MABAC, Personnel Selection 


\section{Giriş}

Küresel rekabetin artması ile birlikte işletmeler verimliliği artırmak amacıyla kalifiyeli personellerin istihdamını artırmaya başlamıştır. Kalifiye personeller bir işletmenin en mühim kaynakları içinde gösterilmektedir (Ulutaş vd., 2018). Kalifiye personelin iş tecrübesi, iş ile ilgili bilgiye haiz olması ve işe yatkınlığ vb. becerileri işletmelerin başarısında etkin bir rol oynamaktadır. Kalifiye personel istihdamı bu sebepten dolayı önemli bir süreç olarak görülmektedir. Personel değerlendirmesinde amaç; açlan pozisyona başvuran adayları uygun kriterler göz önünde bulundurularak adayların performanslarını ölçmek ve pozisyona en uygun adayı belirlemektir.

İhtiyaçlara yönelik bilince sahip olarak veya bilince sahip olmayarak bir şekilde gerçekleştirilen seçime karar verme denir (Yavaş vd., 2014). Karar verme işlemini yürüten/gerçekleştiren kişiler karar verici olarak adlandırılır. İşletmelerdeki karar vericiler, firmanın kâr, maliyet, üretim, iş gücü gibi önemli işlevlerini yerine getirirken her zaman çok kriterli farklı problemlerle karşılaşmaktadırlar (Akhisar ve Tunay, 2015). Personel değerlendirmesi de bu problemlerin en önemlilerinden biridir. Personel değerlendirme sürecinin çok kriterli olması ve hem kalitatif hem de kantitatif kriterlerin mevcudiyeti süreci fazla kompleks bir duruma getirmektedir (Tuş ve Adalı, 2018). Ayrıca personel değerlendirmesi gerçekleştirilirken birden fazla karar vericinin tercihlerine ihtiyaç duyulur. Çok kriterli karar verme yöntemleri, farklı karar vericilerin tercihlerinin birleştirilmesine imkan verdiği bilinmektedir (Atici vd., 2015). Hem personel değerlendirmesinde ve seçiminde birden fazla kriterin yer alması hem de bu değerlendirme ve seçim sürecine birden fazla karar vericinin dâhil olmasından dolayı bu problemin çözümünde bir çok kriterli karar verme (ÇKKV) yöntemi kullanılması uygun olacaktır.

$\mathrm{Bu}$ çalışmada Entropi ve MABAC (multi-attributive border approximation area comparison) (Çok Nitelikli Sınır Yaklaşım Alanı Kıyaslaması) yöntemlerinden oluşan bir ÇKKV modeli ile bir mobilya atölyesi için en uygun pazarlama yöneticisi belirlenmiştir. Bu çalışma iki açıdan literatüre katkı sunmayı hedeflemektedir. İlk olarak MABAC yöntemi ile ilgili Türkçe literatürde az sayıda yayın bulunmaktadır (Ayçin, 2019; Bakır, 2019). Ayrıca Entropi ve MABAC yöntemlerinin birlikte kullanımı ile 
ilgili makale sayısı literatürde az sayıdadır. Bu çalışma yukarıdaki araştırma boşluklarını doldurarak literatüre katkı sunmayı amaçlamaktadır.

Çalışmanın devamı şu şekilde organize edilmiştir. İkinci bölümde personel seçimi ve bu çalışmada kullanılan yöntemler ile ilgili literatür sunulmuştur. Üçüncü bölümde problemin çözümü için önerilen ÇKKV modeli ile ilgili bilgiler gösterilmiştir. Dördüncü bölümde önerilen ÇKKV modelin uygulaması sunulmuştur. Beşinci bölümde çalışmanın sonuçları ve gelecek çalışmalar için öneriler sunulmuştur.

\section{Literatür Taraması}

Personel seçimi, yönetimde önemli bir süreçtir (Kabak vd., 2012). Bundan dolayı ÇKKV yöntemlerinin kullanımı ile personel seçimi ile ilgili literatürde birçok çalışma yapılmıştır. Bu çalışmalardan bazıları Tablo 1'de özetlenmiştir.

Tablo 1. Personel Seçimi İle İlgili Çalışmalar

\begin{tabular}{|c|c|c|}
\hline Yazarlar & Problem & Yöntemler \\
\hline Yıldız ve Deveci (2013) & $\begin{array}{l}\text { Teknoloji firması için mü- } \\
\text { hendis seçimi }\end{array}$ & $\begin{array}{l}\text { Bulanık VIKOR (VlseKriijumsko } \\
\text { Optimizacijo I Kompromisno Re- } \\
\text { senje) }\end{array}$ \\
\hline $\begin{array}{l}\text { Vatansever ve Oncel } \\
(2014)\end{array}$ & $\begin{array}{l}\text { İşletme bölümüne Araş- } \\
\text { tırma Görevlisi alımı }\end{array}$ & $\begin{array}{l}\text { Bulanık AHP (Analitik Hiyerarşi } \\
\text { Prosesi) ve Bulanı TOPSIS (Tech- } \\
\text { nique for Order Preference by Si- } \\
\text { milarity to Ideal Solution) }\end{array}$ \\
\hline Eroğlu vd. (2014) & $\begin{array}{l}\text { Bir firmanın muhasebe ve } \\
\text { pazarlama departmanı } \\
\text { için personel seçimi }\end{array}$ & ORESTE \\
\hline Tepe ve Görener (2014) & $\begin{array}{l}\text { İletişim sektöründe bulu- } \\
\text { nan bir işletme için ara } \\
\text { kademe yönetici personel } \\
\text { seçimi }\end{array}$ & $\begin{array}{l}\text { AHP ve MOORA (Multi Objective } \\
\text { Optimization on the basis of Ratio } \\
\text { Analysis) }\end{array}$ \\
\hline Alguliyev vd. (2015) & Doktora öğrencisi seçimi & $\begin{array}{l}\text { En kötü-durum metodu ve değişti- } \\
\text { rilmiş VIKOR yöntemi }\end{array}$ \\
\hline Özbek (2015) & $\begin{array}{l}\text { Meslek Yüksek Okulu için } \\
\text { müdür seçimi }\end{array}$ & AHP ve MOORA-MULTIMOORA \\
\hline Bedir ve Eren (2015) & $\begin{array}{l}\text { Bir hazır giyim mağazası } \\
\text { için satış danışmanı se- } \\
\text { çimi }\end{array}$ & AHP ve PROMETHEE \\
\hline Liu vd. (2015) & $\begin{array}{l}\text { Bir hastane için başhem- } \\
\text { şire seçimi }\end{array}$ & Aralıklı 2-boyutlu VIKOR \\
\hline
\end{tabular}


Değermenci ve Ayaz

(2016)

Özbek ve Erol (2016)

Akar ve Çakır (2016)

Kundakcı (2016)

Khandekar ve

Chakraborty (2016)

Turskis vd. (2017)

Urosevic vd. (2017)

Deliktas ve Ustun (2017)

Çelikbilek (2018)

Ulutaş vd. (2018)

Tuş ve Adalı (2018)

Efe ve Kurt (2018)

Akça vd. (2018)

Eşiyok ve Eren (2018)

Karabasevic vd. (2018)

Ji vd. (2018)

Korkmaz (2019)
Bir katılım bankası için uzman yardımcısı seçimi Bir tekstil işletmesi için işgören seçimi

Lojistik sektöründe yer alan bir firma için lojistik operasyon elemanı seçimi Teknoloji firması için personel seçimi

Büyük ölçekli bir imalat organizasyonunun satın alma departmanı için müdür yardımcısı seçimi Emlak ve Ekonomi Ofisi Yöneticisi Seçimi

Önerilen yöntemlerin sayısal örnekte kullanımı

Erasmus için öğrenci seçimi

Sağlık endüstrisinde yönetici seçimi

Elektrik aksamı üreten bir fabrika için üretim planlama yöneticisi seçimi Bir tekstil firması için pazarlama asistanı seçimi

Bir liman işletmesi için insan kaynakları uzmanı seçimi

Kamu hastanesi için finans yöneticisi seçimi

Bir medya kuruluşu için haber editörü seçimi

Bir IT firması için personel seçimi

Önerilen yöntemin sayısal örnekle çözümü

Bir lojistik şirketi için lojistik operasyon personeli seçimi

\section{Bulanık TOPSIS}

AHP ve VIKOR

Bulanık AHP ve MOORA

GİA (Gri İlişkisel Analizi)

Bulanık Aksiyomatik Tasarım Yöntemi

AHP, Bulanık ARAS (Additive Ratio Assessment) ve Bulanık EDAS (Evaluation based on Distance from Average Solution) SWARA (Step-wise Weight Assessment Ratio Analysis) ve WASPAS (Weighted Aggregated Sum Product Assessment)

Bulanık MULTIMOORA ve Çok seçenekli konik hedef programlama

Gri AHP ve Gri MOORA

Bulanık AHP ve Bulanık GİA

CRITIC, CODAS (Combinative Distance-based Assessment), PSI (Preference Selection Index) Bulanık AHP ve Bulanık TOPSIS

Analitik A $\breve{g}$ Süreci

GİA

SWARA ve EDAS

Sezgisel TODIM

TOPSIS 


\begin{tabular}{lll} 
Nabeeh vd. (2019) & Mısır'daki akıllı köyde & Sezgisel TOPSIS \\
& yer alan müş̧eri hizmet & \\
& bölümü için yönetici se- & \\
& çimi & \\
Yalçın ve Pehlivan & Türkiye'deki bir üretim & Sezgisel Bulanık CODAS \\
(2019) & firması için mavi yakalı & \\
& personel seçimi & \\
\hline
\end{tabular}

Entropi yöntemi karar matrisinde yer alan değerleri kullanarak kriter ağırlıklarını elde edebilen bir yöntemdir. Diğer ağırlık bulma için kullanılan ÇKKV yöntemlerinden (SWARA, AHP ve Analitik Ağ Süreci) farklı olarak kriterler için ayrı bir veri setine ihtiyaç duymamaktadır. Literatürde Entropi yöntemi ile ilgili son yıllarda birçok çalışma yapılmıştır. Bu çalışmalardan bazıları şunlardır; otomobil firmalarının performans ölçümü (Ömürbek vd., 2016), bankacılık sektöründe performans ölçümü (Akçakanat vd., 2017), esnek üretim sistemi seçimi (Ulutaş, 2018), sigorta firmalarının değerlendirilmesi (Perçin ve Sönmez, 2018), havayolu işletmelerinde hizmet kalitesinin değerlendirilmesi (Bakır ve Atalık, 2018), bireysel emeklilik şirketlerinin performans değerlendirmesi (Bayrakçı ve Aksoy, 2019), ve vergi gelirleri bakımından OECD ülkelerinin performanslarının değerlendirilmesi (Koca vd., 2019).

MABAC yöntemi 2015 yılında Pamučar ve Ćirović tarafından geliştirilmiştir ve forklift seçiminde kullanılmıştır (Pamučar ve Ćirović, 2015). MABAC yöntemi yeni geliştirilmesine rağmen farklı metotlar ve yaklaşımlar ile birleştirilerek birçok çalışmada kullanılmıştır. Peng ve Yang (2016) bulanık sezgisel choquet integrali ile MABAC yöntemini birlikte kullanmışlardır. Xue vd. (2016) malzeme seçimi için aralık değerli sezgisel bulanık MABAC yöntemini uygulamışlardır. Gigović vd. (2017) coğrafi bilgi sistemleri, DEMATEL, Analitik Ağ Süreci ve MABAC yöntemlerini birlikte kullanarak rüzgar çiftlikleri için en uygun yeri belirlemeye çalışmışlardır. Yu vd. (2017) aralıklı tip 2 bulanık olasılıklı MABAC yöntemi ile bir web sitesinden otel seçimi yapmışlardır. MABAC yönteminde farklı yaklaşımlarda kullanılmıştır. Örneğin bulanık kaba küme teorili (Pamučar vd., 2018), kaba küme teorili (Roy vd., 2018) ve tereddütlü (hesitant) bulanık MABAC (Sun vd., 2018) yöntemleri literatürde önerilmiştir. Yabancı literatürde bu kadar çok çalışma varken Türkçe literatürde sadece 
iki yayın (Ayçin, 2019; Bakır, 2019) tespit edilmiştir. Gelecek bölümde bu çalışmada kullanılan metotlar anlatılmıştır.

\section{Metodoloji}

Bu çalışmada Entropi ve MABAC yöntemleri kullanılmıştır. Entropi yöntemi ile kriter ağırlıkları elde edilirken, MABAC yöntemi alternatiflerin sıralanmasında kullanılmıştır. Entropi yöntemi aşağıdaki adımlardan oluşmaktadır (Wang ve Lee, 2009):

Adım 1-1: İlk olarak karar matrisi düzenlenir. Eşitlik 1'de karar matrisi gösterilmiştir.

$$
F=\left[f_{i j}\right]_{m \times n}=\left[\begin{array}{cccc}
f_{11} & f_{12} & \cdots & f_{1 n} \\
f_{21} & f_{22} & \cdots & f_{2 n} \\
\vdots & \vdots & \vdots & \vdots \\
f_{m 1} & f_{m 2} & \cdots & f_{m n}
\end{array}\right]
$$

Yukarıdaki eşitlikte yer alan $f_{i j}, i$.alternatifin $j$. kriterde gösterdiği performansı tanımlamaktadır.

Adım 1-2: Bu karar matrisi aşağıdaki eşitlikle normalize edilir.

$$
e_{i j}=\frac{f_{i j}}{\sum_{i=1}^{m} f_{i j}}
$$

Adım 1-3: Kriterlere ait entropi değerleri $\left(E_{j}\right)$ eşitlik 3 ile bulunur.

$$
E_{j}=-\frac{\sum_{i=1}^{m} e_{i j} \ln \left(e_{i j}\right)}{\ln (m)}
$$

Adım 1-4: Aşağıdaki eşitlikle her bir kriterin ağırlığı $\left(w_{j}\right)$ hesaplanır.

$$
w_{j}=\frac{1-E_{j}}{\sum_{j=1}^{n}\left(1-E_{j}\right)}
$$


Bulunan kriter ă̆ırlıkları MABAC yöntemine aktarılır. MABAC yöntemi aşağıda gösterilmiş olan adımlardan oluşmaktadır (Pamučar ve Ćirović, 2015).

Adım 2-1: İlk adım karar matrisini oluşturmaktır. İlk adım eşitlik 1'de gösterilmiştir.

Adım 2-2: Karar matrisi aşağıdaki eşitlikler ile normalize edilir. Eşitlik 5 faydalı kriterler için eşitlik 6 ise maliyet kriterleri için kullanılacaktır.

$$
\begin{aligned}
d_{i j} & =\frac{f_{i j}-\min \left(f_{i}\right)}{\max \left(f_{i}\right)-\min \left(f_{i}\right)} \\
d_{i j} & =\frac{f_{i j}-\max \left(f_{i}\right)}{\min \left(f_{i}\right)-\max \left(f_{i}\right)}
\end{aligned}
$$

Adım 2-3: Eşitlik 7 ile ağırlıklandırılmış matris oluşturulur.

$$
b_{i j}=w_{j} \times\left(d_{i j}+1\right)
$$

Adım 2-4: Eşitlik 8 ile sınır yakınlık alanı matrisi elde edilir. Eşitlikler 8 ve 9'da gösterilen $g_{i}$ değeri sınır yakınlık alanı matrisinin $(G)$ elemanıdır.

$$
\begin{aligned}
g_{i} & =\left(\prod_{i=1}^{m} b_{i j}\right)^{1 / m} \\
G & =\left[g_{i}\right]_{1 \times n}
\end{aligned}
$$

Adım 2-5: Alternatiflerin sınır yakınlık alanına olan uzaklıkları ( $Q$ ) matrisi eşitlik 10 ile elde edilir.

$$
Q=B-G=\left[\begin{array}{cccc}
b_{11}-g_{1} & b_{12}-g_{2} & \cdots & b_{1 n}-g_{n} \\
b_{21}-g_{1} & b_{22}-g_{2} & \cdots & b_{2 n}-g_{n} \\
\cdots & \cdots & \cdots & \cdots \\
b_{m 1}-g_{1} & b_{m 2}-g_{2} & \cdots & b_{m n}-g_{n}
\end{array}\right]=\left[\begin{array}{cccc}
q_{11} & q_{12} & \cdots & q_{1 n} \\
q_{21} & q_{22} & \cdots & q_{2 n} \\
\cdots & \cdots & \cdots & \cdots \\
q_{m 1} & q_{m 2} & \cdots & q_{m n}
\end{array}\right]
$$

Adım 2-6: Sınır yakınlık alanına göre konumların belirlenmesi yapılır. Eşitlik 11'de gösterildiği gibi bir alternatif 3 konumda bulunabilir. Bir al- 
ternatif en iyi alternatif olması için çoğu $q_{i j}$ değerlerinin 0'dan büyük olması diğer bir deyişle üst yakınlık alanında $\left(G^{+}\right)$bulunması gerekmektedir. Bunun dışında alternatif iki farklı konumda bulunabilir. Bunlar alt yakınlık alanı $\left(G^{-}\right)$ve sınır yakınlık alanı $(G)$ olmaktadır. Alternatiflerden alt yakınlık alanına yakın olanlar negatif ideal alternatiflerdir yani kötü performansa sahip alternatiflerdir.

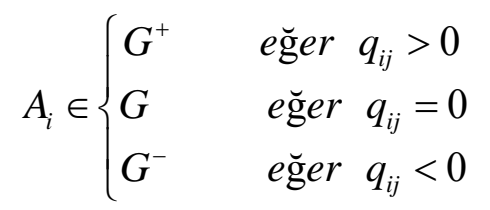

Adım 2-7: Her bir alternatif için sınır yakınlık alanına olan uzaklık $\left(q_{i j}\right)$ değerleri toplanarak $S_{i}$ değerleri elde edilir. En iyi alternatif, en yüksek $S_{i}$ değerine sahip olan alternatif olarak belirlenir.

$$
S_{i}=\sum_{j=1}^{n} q_{i j}
$$

\section{Uygulama}

Yöntemlerin uygulaması bir mobilya atölyesinde yapılmıştır. Bu mobilya atölyesi yerel tüketicinin talebine uygun olarak masa, sandalye, dolap, koltuk ve kanepe vb. birçok mobilya üretmektedir. Bu firma üretilen mobilyaların pazarlamasını uzman personelin yapmasını tercih etmektedir. Bunun için firma pazarlama yöneticisi istihdam etmek istemektedir. Firmanın yöneticilerine literatürde sıkça yer alan kriterlerin listesi gösterilmiştir ve bu listeden uygulamada kullanılmak üzere kriterleri seçmeleri istenmiştir. Firmanın yöneticileri bu listeden seçimde kullanılacak kriterleri belirlemişlerdir. Belirlenen kriterler aşağıda gösterilmiştir:

KR1: İş Tecrübesi

KR2: Eğitim

KR3: Takım Çalışmasına Yatkınlık

KR4: Bilgisayar Becerileri

KR5: Yabanc1 Dil Seviyesi

KR6: İletişim Becerileri 
KR7: İkna Kabiliyeti

KR8: Talep Edilen Ücret

Bu pozisyona toplam 14 kişi başvuruda bulunmuştur. Adaylardan dördü eğitim ve askerlik durumundan, diğer dördü getirdikleri referans mektuplarındaki referanslara ulaşılamamasından dolayı doğrudan elenmişlerdir. Bu elemelerden sonra altı adayın her biri mülakat ve uygulama sinavlarına tabi tutulmuştur. Bu sınavların sonuçlarına göre karar matrisi oluşturulmuştur. Karar matrisi oluşturulurken, adaylara KR1 için başka firmalardaki çalışma süreleri sorulmuştur ve KR8 kriteri için ne kadar ücret talep ettikleri adaylara sorulmuştur. KR2 için ise adaylara eğitim durumları sorulmuş olup, eğitim durumuna (lisans ise 1, yüksek lisans ise 2, doktora ise 3) göre adaya puan verilmiştir Diğer kriterler değerlendirilirken mülakat ve uygulama sınavlarında göstermiş oldukları performanslar dikkate alınmıştır. Ayrıca KR8 kriteri maliyet kriteri iken diğer kriterler faydalı kriterler olarak değerlendirilmiştir. Tablo 2, karar matrisini göstermektedir.

Tablo 2. Karar Matrisi

\begin{tabular}{lllll}
\hline \multicolumn{1}{c}{ Kriterler } & KR1 & KR2 & KR3 & KR4 \\
\hline Alternatifler & & & & \\
Alternatif 1 & 2 & 1 & 4 & 7 \\
Alternatif 2 & 4 & 1 & 5 & 6 \\
Alternatif 3 & 3 & 2 & 6 & 6 \\
Alternatif 4 & 5 & 1 & 5 & 7 \\
Alternatif 6 & 4 & 2 & 5 & 6 \\
\hline Kriterler & 3 & 2 & 6 & 6 \\
\hline KR5 & & KR6 & KR7 & KR8 \\
\hline Alternatifler & & & & \\
Alternatif 1 & 6 & 6 & 7 & 3000 \\
Alternatif 3 & 7 & 7 & 6 & 3500 \\
Alternatif 4 & 5 & 6 & 8 & 4000 \\
Alternatif 5 & 6 & 7 & 7 & 3000 \\
Alternatif 6 & 7 & 7 & 6 & 3000 \\
\hline
\end{tabular}


Bu matrise Entropi yöntemi uygulanırsa her bir kritere ait entropi değerleri ve kriter ağırlıkları elde edilir. Bu değerler Tablo 3'te gösterilmiştir. Kriter ağırlıkları elde edildikten sonra MABAC yöntemine aktarılmıştır.

Tablo 3. Entropi Yönteminin Sonuçları

\begin{tabular}{|c|c|c|c|c|}
\hline Konuçlar & KR1 & KR2 & KR3 & KR4 \\
\hline$E_{j}$ & 0,978 & 0,968 & 0,995 & 0,998 \\
\hline $1-E_{j}$ & 0,022 & 0,032 & 0,005 & 0,002 \\
\hline$w_{j}$ & 0,293 & 0,427 & 0,067 & 0,027 \\
\hline Sonuçlar & KR5 & KR6 & KR7 & KR8 \\
\hline$E_{j}$ & 0,996 & 0,998 & 0,996 & 0,996 \\
\hline $1-E_{j}$ & 0,004 & 0,002 & 0,004 & 0,004 \\
\hline$w_{j}$ & 0,053 & 0,027 & 0,053 & 0,053 \\
\hline
\end{tabular}

Tablo 2' de gösterilen karar matrisine eşitlik 5 ve 6 uygulanır. Böylece MABAC yöntemi için normalize edilmiş karar matrisi oluşturulur. Bu matris Tablo 4'te gösterilmiştir.

Tablo 4. Normalizasyon Edilmiş Karar Matrisi

\begin{tabular}{|c|c|c|c|c|}
\hline Alternatifler & KR1 & KR2 & KR3 & KR4 \\
\hline Alternatif 1 & 0 & 0 & 0 & 1 \\
\hline Alternatif 2 & 0,667 & 0 & 0,5 & 0 \\
\hline Alternatif 3 & 0,333 & 1 & 1 & 0 \\
\hline Alternatif 4 & 1 & 0 & 0,5 & 1 \\
\hline Alternatif 5 & 0,667 & 1 & 0,5 & 0 \\
\hline Alternatif 6 & 0,333 & 1 & 1 & 0 \\
\hline Kriterler & KR5 & KR6 & KR7 & KR8 \\
\hline \multicolumn{5}{|l|}{ Alternatifler } \\
\hline Alternatif 1 & 0,5 & 0 & 0,5 & 1 \\
\hline
\end{tabular}




\begin{tabular}{lllll} 
Alternatif 2 & 1 & 1 & 0 & 0,5 \\
Alternatif 3 & 0 & 0 & 1 & 0 \\
Alternatif 4 & 0,5 & 1 & 0,5 & 1 \\
Alternatif 5 & 1 & 1 & 0 & 1 \\
Alternatif 6 & 0,5 & 0 & 0 & 0,5 \\
\hline
\end{tabular}

Eşitlik 7 ile ağırlıklandırılmış matris elde edilir. Bu matris Tablo 5'te gösterilmiştir.

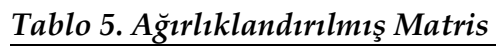

\begin{tabular}{lllll}
\hline Kriterler & KR1 & KR2 & KR3 & KR4 \\
\hline Alternatifler & & & & \\
Alternatif 2 & 0,293 & 0,427 & 0,067 & 0,054 \\
Alternatif 3 & 0,488 & 0,427 & 0,101 & 0,027 \\
Alternatif 4 & 0,391 & 0,854 & 0,134 & 0,027 \\
Alternatif 5 & 0,586 & 0,427 & 0,101 & 0,054 \\
Alternatif 6 & 0,488 & 0,854 & 0,101 & 0,027 \\
Kriterler & 0,391 & 0,854 & 0,134 & 0,027 \\
Alternatifler & KR5 & KR6 & KR7 & KR8 \\
\hline Alternatif 1 & & & & \\
Alternatif 2 & & & & \\
Alternatif 3 & 0,080 & 0,027 & 0,080 & 0,106 \\
Alternatif 4 & 0,106 & 0,054 & 0,053 & 0,080 \\
Alternatif 5 & 0,053 & 0,027 & 0,106 & 0,053 \\
Alternatif 6 & 0,080 & 0,054 & 0,080 & 0,106 \\
\hline
\end{tabular}

Eşitlik 8 yardımı ile sınır yakınlık alanı matrisi oluşturulur. Tablo 6'da bu matris sunulmuştur.

Tablo 6. Sinır Yakınlık Alanı Matrisi

\begin{tabular}{lllll}
\hline & KR1 & KR2 & KR3 & KR4 \\
\hline$g_{i}$ & 0,429 & 0,604 & 0,104 & 0,034 \\
\hline$g_{i}$ & KR5 & KR6 & KR7 & KR8 \\
\hline
\end{tabular}


Eşitlik 10 ile alternatiflerin sınır yakınlık alanından uzaklıkları matrisi bulunur. Tablo 7'de bu matris gösterilmiştir.

Tablo 7. Alternatiflerin Sınır Yakınlık Alanından Uzaklıkları Matrisi

\begin{tabular}{lllll}
\hline & KR1 & KR2 & KR3 & KR4 \\
Alternatifler & & & & \\
\hline Alternatif 1 & $-0,136$ & $-0,177$ & $-0,037$ & 0,02 \\
Alternatif 2 & 0,059 & $-0,177$ & $-0,003$ & $-0,007$ \\
Alternatif 3 & $-0,038$ & 0,25 & 0,03 & $-0,007$ \\
Alternatif 4 & 0,157 & $-0,177$ & $-0,003$ & 0,02 \\
Alternatif 5 & 0,059 & 0,25 & $-0,003$ & $-0,007$ \\
Alternatif 6 & $-0,038$ & 0,25 & 0,03 & $-0,007$ \\
\hline Kriterler & KR5 & KR6 & KR7 & KR8 \\
Alternatifler & & & & \\
\hline Alternatif 1 & & & & \\
Alternatif 2 & $-0,002$ & $-0,011$ & 0,012 & 0,02 \\
Alternatif 3 & 0,024 & 0,016 & $-0,015$ & $-0,006$ \\
Alternatif 4 & $-0,029$ & $-0,011$ & 0,038 & $-0,033$ \\
Alternatif 5 & $-0,002$ & 0,016 & 0,012 & 0,02 \\
Alternatif 6 & 0,024 & 0,016 & $-0,015$ & 0,02 \\
\hline
\end{tabular}

Tablo 7'de gösterilen matrise eşitlik 12 uygulanarak sonuçlara ve alternatiflerin sıralamasına ulaşılabilir. Tablo 8, sonuçları göstermektedir.

Tablo 8. Alternatiflerin Sınır Yakınlık Alanından Uzaklıkları Matrisi

\begin{tabular}{lll}
\hline & $S_{i}$ & Siralama \\
Alternatifler & & \\
\hline Alternatif 1 & $-0,311$ & 6 \\
Alternatif 2 & $-0,109$ & 5 \\
Alternatif 3 & 0,200 & 3 \\
Alternatif 4 & 0,043 & 4 \\
Alternatif 5 & 0,344 & 1 \\
Alternatif 6 & 0,201 & 2 \\
\hline
\end{tabular}

Tablo 8'deki sonuçlara göre en iyi aday "Alternatif 5" kodlu aday olarak belirlenmiştir. 


\section{Sonuçlar}

Kalifiye personelin iş ile ilgili bilgiye sahip olması, iş deneyiminin olması ve işe yatkınlı̆̆ vb. yetenekleri işletmelerin başarısında etkin bir rol oynamaktadır. Bu sebepten dolayı kalifiye personel istihdamının yapılması mühim bir süreç olarak görülmektedir. Personel değerlendirmesinde amaç; açılan pozisyona başvuran adayları uygun kriterler göz önünde bulundurularak adayların performanslarını ölçmek ve pozisyona en uygun adayı belirlemektir. Personel değerlendirmesinde ve seçiminde birden fazla kriter göz önünde bulundurulduğu için ve bu süreçte birden fazla karar vericinin görüşüne başvurulduğu için ÇKKV yöntemlerinden faydalanılabilir. Bu çalışmada Entropi ve MABAC yöntemlerinden oluşan bir ÇKKV modeli önerilmiştir. Bu çalışma iki açıdan literatüre katkı sunmayı hedeflemektedir. İlk olarak MABAC yöntemi ile ilgili Türkçe literatürde az sayıda yayın bulunmaktadır. Ayrıca Entropi ve MABAC yöntemlerinin birlikte kullanımı ile ilgili makale sayısı literatürde az sayıdadır. Bu çalışma yukarıdaki araştırma boşluklarını doldurarak literatüre katkı sunmayı amaçlamaktadır. Çalışmada önerilen ÇKKV modeli bir mobilya atölyesi için en uygun pazarlama yöneticisi belirlenmesinde kullanılmıştır. Çalışmada önerilen modelin sonuçlarına göre aday alternatifleri şu şekilde sıralanmıştır; Alternatif $5>$ Alternatif $6>$ Alternatif $3>$ Alternatif $4>$ Alternatif $2>$ Alternatif 1 . Gelecek çalışmalar, MABAC yöntemini farklı ÇKKV problemleri (tedarikçi seçimi, yer seçimi ve tesis seçimi vb.) için kullanabilirler. 


\title{
EXTENDED ABSTRACT
}

\section{Personnel Selection with Entropy and MABAC Methods}

\author{
Alptekin Ulutaş \\ Sivas Cumhuriyet University
}

With the increase in global competition, enterprises have started to increase the employment of qualified personnel in order to increase productivity. Qualified personnel is listed among the most important resources of an enterprise (Ulutaş et al., 2018). Qualified personnel who have some skills, such as work experience, knowledge of the job and tendency to the job, etc. play an active role in the success of businesses. Therefore, the employment of qualified personnel is seen as an important process. The purpose of personnel evaluation and selection is to measure the performance of the candidates applying to the opened position while considering the appropriate criteria and to determine the most suitable candidate for the position. Since multiple criteria are included in the evaluation and selection of personnel and more than one decision maker is involved in this evaluation and selection process, it is appropriate to use an MCDM method to solve this problem. In this study, an MCDM model consisting of Entropy and MABAC methods are used to determine the most suitable marketing manager for a furniture workshop. This study aims to contribute to the literature from two sides. Firstly, there are few publications in Turkish literature about MABAC method (Ayçin, 2019; Bakır, 2019). In addition, the number of articles related to the use of Entropy and MABAC methods together in the literature is few. This study aims to contribute to the literature by filling the gaps above-mentioned.

\section{Literature Review Related to using of MABAC Method}

The MABAC method was developed in 2015 by Pamučar and Ćirović and was used in forklift selection (Pamučar and Ćirović, 2015). Although the MABAC method is newly developed, it has been used in many studies by combining with different methods and approaches. For example, pythagorean fuzzy choquet integral based MABAC was developed by Peng and 
Yang (2016). For material selection problem, Xue et al. (2016) proposed an interval-valued intuitionistic fuzzy MABAC. Gigović et al. (2017) integrated Geographic Information Systems, DEMATEL, MABAC and Analytic Network Process in order to choose the most appropriate location of wind farms. In order to choose hotels on a tourism website, an interval type-2 fuzzy likelihood-based MABAC was developed by Yu et al. (2017). MABAC method has been used with different approaches. For instance, fuzzy rough set theory (Pamučar et al., 2018), rough set theory (Roy et al., 2018) and hesitant fuzzy MABAC (Sun et al., 2018) methods have been proposed in the literature. While there are so many studies in foreign literature, only two publications have been identified in Turkish literature (Ayçin, 2019; Bakır, 2019).

\section{Application of Proposed Model}

The methods were applied in a furniture workshop. This furniture workshop manufactures many items of furniture in accordance with the demand of the local customer, such as tables, chairs, cabinets, armchairs and sofas and so on. This company would like to work with expert personnel to market the produced furniture. For this, the company would like to employ a marketing manager. The managers of the company have been shown a list of the criteria frequently used in the literature and were asked to select the criteria to be used in the application of the model. The managers of the company have determined the criteria to be used in this list. The criteria set are shown below:

CR1: Job Experience

CR2: Education

CR3: Predisposition to Teamwork

CR4: Computer Skills

CR5: Foreign Language Level

CR6: Communication Skills

CR7: Persuasion Skills

CR8: Requested Wage

A total of 14 people applied for this position. Four of the candidates were directly eliminated due to their education status and military obligations, while the other four were directly eliminated due to the inaccessibility of the references in their reference letters. After this pre-elimination, each of the six 
candidates was subjected to interview and practice exams. Decision matrix was formed according to the results of these exams. While determining CR1, candidates were asked to working time in other companies. While determining CR2, if the candidate has an undergraduate degree, the candidate takes one point. If he/she has a master degree, he/she takes two points. If he/she has a doctorate degree, he/she takes three points. When identifying CR8, the applicants were asked how much money they requested for work. When evaluating the other criteria, their performance in the interview and practice exams were taken into consideration. In addition, the CR8 criterion was taken into account as the cost criterion while the other criteria were considered as beneficial criteria. After all these evaluations, the decision matrix was structured. First, Entropy method was applied to the decision matrix to obtain criteria weights, then MABAC method was applied to matrix to rank alternatives. According to the results of the proposed model, the best candidate alternative is determined as "Alternative 5" among 6 alternatives. Future studies may use the MABAC method for different MCDM problems (supplier selection, site selection, and facility selection, etc.).

\section{Kaynakça / References}

Akar, G. S. ve Çakır, E. (2016). Lojistik sektöründe bütünleştirilmiş bulanık AHP-MOORA yaklaşımı ile personel seçimi. Yönetim Ve Ekonomi Araştırmaları Dergisi, 14(2), 185-199.

Akça, N., Sönmez, S., Gür, Ş., Yılmaz, A. ve Eren, T. (2018). Kamu hastanelerinde analitik ağ süreci yöntemi ile finans yöneticisi seçimi. Optimum Ekonomi ve Yönetim Bilimleri Dergisi, 5(2), 133-146.

Akçakanat, Ö., Eren, H., Aksoy, E. ve Ömürbek, V. (2017). Bankacılık sektöründe Entropi ve Waspas yöntemleri ile performans değerlendirmesi. Süleyman Demirel Üniversitesi İktisadi ve İdari Bilimler Fakültesi Dergisi, 22(2). 285-300.

Akhisar, I. ve Tunay, N. (2015, May). Performance ranking of Turkish life insurance companies using AHP and TOPSIS. In Management International Conference. Portoroz, Slovenia (pp. 241-250).

Alguliyev, R. M., Aliguliyev, R. M. ve Mahmudova, R. S. (2015). Multicriteria personnel selection by the modified fuzzy VIKOR method. The Scientific World Journal, 2015. 
Atici, K. B., Simsek, A. B., Ulucan, A. ve Tosun, M. U. (2015). A GIS-based multiple criteria decision analysis approach for wind power plant site selection. Utilities Policy, 37, 86-96.

Ayçin, E. (2019). Kurumsal kaynak planlama (KKP) sistemlerinin seçiminde MACBETH ve MABAC yöntemlerinin bütünleşik olarak kullanılmas1. Atatürk Üniversitesi İktisadi ve İdari Bilimler Dergisi, 33(2), 533552.

Bakır, M. ve Atalık, Ö. (2018). Entropi ve Aras yöntemleriyle havayolu işletmelerinde hizmet kalitesinin değerlendirilmesi. İşletme Araştırmaları Dergisi, 10(1), 617-638.

Bakır, M. (2019). SWARA ve MABAC yöntemleri ile havayolu işletmelerinde eWOM'a dayalı memnuniyet düzeyinin analizi. İmir İtisat Dergisi, 34(1), 51-66.

Bayrakçı, E. ve Aksoy, E. (2019). Bireysel emeklilik şirketlerinin entropi ağırlıklı ARAS ve COPRAS yöntemleri ile karşılaştırmalı performans değerlendirmesi. Business and Economics Research Journal, 10(2), 415434.

Bedir, N. ve Eren, T. (2015). AHP-PROMETHEE yöntemleri entegrasyonu ile personel seçim problemi: Perakende sektöründe bir uygulama. Sosyal Bilimler Araştırma Dergisi, 4(4), 46-58.

Çelikbilek, Y. (2018). Using an integrated grey AHP-MOORA approach for personnel selection: An application on manager selection in the health industry. Alphanumeric Journal, 6(1), 69-82.

Değermenci, A. ve Ayvaz, B. (2016). Bulanık ortamda TOPSIS yöntemi ile personel seçimi: Katılım bankacılığı sektöründe bir uygulama. İstanbul Ticaret Üniversitesi Fen Bilimleri Dergisi, 15(30), 77-93.

Deliktas, D. ve Ustun, O. (2017). Student selection and assignment methodology based on fuzzy MULTIMOORA and multichoice goal programming. International Transactions in Operational Research, 24(5), 11731195.

Efe, B. ve Kurt, M. (2018). Bir liman işletmesinde personel seçimi uygulamas1. Karaelmas Fen ve Mühendislik Dergisi, 8(2), 417-427.

Eroğlu, E., Yıldırım, B. F. ve Özdemir, M. (2014). Çok kriterli karar vermede "ORESTE" yöntemi ve personel seçiminde uygulanması. Istanbul Management Journal, 25(76), 1-19. 
Eşiyok, Y. ve Eren, Ö. (2018). Personel seçim probleminin gri ilişkisel analiz yöntemi ile çözülmesi: Medya sektöründe bir uygulama. Business $\mathcal{E}$ Management Studies: An International Journal, 6(4), 898-919.

Gigović, L., Pamučar, D., Božanić, D. ve Ljubojević, S. (2017). Application of the GIS-DANP-MABAC multi-criteria model for selecting the location of wind farms: A case study of Vojvodina, Serbia. Renewable Energy, 103, 501-521.

Ji, P., Zhang, H. Y. ve Wang, J. Q. (2018). A projection-based TODIM method under multi-valued neutrosophic environments and its application in personnel selection. Neural Computing and Applications, 29(1), 221234.

Kabak, M., Burmaoğlu, S. ve Kazançoğlu, Y. (2012). A fuzzy hybrid MCDM approach for professional selection. Expert Systems with Applications, 39(3), 3516-3525.

Karabasevic, D., Zavadskas, E. K., Stanujkic, D., Popovic, G. ve Brzakovic, M. (2018). An approach to personnel selection in the IT industry based on the EDAS Method. Transformations in Business \& Economics, 17(2), 54-65.

Khandekar, A. V. ve Chakraborty, S. (2016). Personnel selection using fuzzy axiomatic design principles. Business: Theory and Practice/Verslas: Teorija ir Praktika, 17(3), 251-260.

Koca, G., Ekinci, F. ve Şimşek, M. (2019). Vergi gelirleri bakımından OECD ülkelerinin performansının bütünleşik entropi-ARAS yöntemi ile değerlendirilmesi. Elektronik Sosyal Bilimler Dergisi, 18(70), 964-985.

Korkmaz, O. (2019). Personnel selection method based on TOPSIS multi-criteria decision-making method. Uluslararası İktisadi ve İdari İncelemeler Dergisi, (23), 1-16.

Kundakc1, N. (2016). Personnel selection with grey relational analysis. Management Science Letters, 6(5), 351-360.

Nabeeh, N. A., Smarandache, F., Abdel-Basset, M., El-Ghareeb, H. A. ve Aboelfetouh, A. (2019). An integrated neutrosophic-TOPSIS approach and its application to personnel selection: A new trend in brain processing and analysis. IEEE Access, 7, 29734-29744.

Liu, H. C., Qin, J. T., Mao, L. X. ve Zhang, Z. Y. (2015). Personnel selection using interval 2-tuple linguistic VIKOR method. Human Factors and Ergonomics in Manufacturing \& Service Industries, 25(3), 370-384. 
Ömürbek, N., Karaatlı, M. ve Balcı, H. F. (2016). Entropi temelli MAUT ve SAW yöntemleri ile otomotiv firmalarının performans değerlemesi. Dokuz Eylül Üniversitesi İktisadi İdari Bilimler Fakültesi Dergisi, 31(1), 227-255.

Özbek, A. (2015). Akademik birim yöneticilerinin MOORA yöntemiyle seçilmesi: Kırıkkale üzerine bir uygulama. Erciyes Üniversitesi Sosyal Bilimler Enstitüsü Dergisi, 1(38), 1-18.

Özbek, A. ve Erol, E. (2016). Analitik hiyerarşi süreci ve VIKOR yöntemleriyle işgören seçimi: Tekstil sektöründe bir uygulama. kırıkkale Üniversitesi Sosyal Bilimler Dergisi, 6(1), 93-108.

Pamučar, D. ve Ćirović, G. (2015). The selection of transport and handling resources in logistics centers using Multi-Attributive Border Approximation area Comparison (MABAC). Expert systems with applications, 42(6), 3016-3028.

Pamučar, D., Petrović, I. ve Ćirović, G. (2018). Modification of the Best-Worst and MABAC methods: A novel approach based on interval-valued fuzzy-rough numbers. Expert systems with applications, 91, 89-106.

Peng, X. ve Yang, Y. (2016). Pythagorean fuzzy Choquet integral based MABAC method for multiple attribute group decision making. International Journal of Intelligent Systems, 31(10), 989-1020.

Perçin, S. ve Sönmez, Ö. (2018). Bütünleşik entropi ağırlık ve TOPSIS yöntemleri kullanılarak Türk sigorta şirketlerinin performansının ölçülmesi. Uluslararası İktisadi ve İdari İncelemeler Dergisi, 18, 565-582.

Roy, J., Chatterjee, K., Bandyopadhyay, A. ve Kar, S. (2018). Evaluation and selection of medical tourism sites: A rough analytic hierarchy process based multi-attributive border approximation area comparison approach. Expert Systems, 35(1), 1-19.

Sun, R., Hu, J., Zhou, J., ve Chen, X. (2018). A hesitant fuzzy linguistic projection-based MABAC method for patients' prioritization. International Journal of Fuzzy Systems, 20(7), 2144-2160.

Tepe, S. ve Görener, A. (2014). Analitik hiyerarşi süreci ve MOORA yöntemlerinin personel seçiminde uygulanması. İstanbul Ticaret Üniversitesi Fen Bilimleri Dergisi, 13(25), 1-14. 
Turskis, Z., Keršulienė, V. ve Vinogradova, I. (2017). A new fuzzy hybrid multi-criteria decision-making approach to solve personnel assessment problems. case study: Director selection for estates and economy office. Economic Computation and Economic Cybernetics Studies and Research, 51(3), 211-229.

Tuş, A. ve Adall, E. A. (2018). Personnel assessment with CODAS and PSI methods. Alphanumeric Journal, 6(2), 243-256.

Ulutaş, A., Özkan, A. M. ve Tağraf, H. (2018). Bulanık analitik hiyerarşi süreci ve bulanık gri ilişkisel analizi yöntemleri kullanılarak personel seçimi yapılması. Elektronik Sosyal Bilimler Dergisi, 17(65), 223-232.

Ulutaş, A. (2018). Entropi temelli ROV yöntemi ile esnek üretim sistemi seçimi. Business and Economics Research Journal, 9(1), 187-194.

Urosevic, S., Karabasevic, D., Stanujkic, D. ve Maksimovic, M. (2017). An approach to personnel selection in the tourism industry based on the SWARA and the WASPAS methods. Economic Computation \& Economic Cybernetics Studies \& Research, 51(1), 75-88.

Vatansever, K. ve Oncel, M. (2014). An implementation of integrated multicriteria decision making techniques for academic staff recruitment. Journal of Management Marketing and Logistics, 1(2), 111-126.

Wang, T. C. ve Lee, H. D. (2009). Developing a fuzzy TOPSIS approach based on subjective weights and objective weights. Expert systems with applications, 36(5), 8980-8985.

Xue, Y. X., You, J. X., Lai, X. D. ve Liu, H. C. (2016). An interval-valued intuitionistic fuzzy MABAC approach for material selection with incomplete weight information. Applied Soft Computing, 38, 703-713.

Yavaş, M., Ersöz, T., Kabak, M. ve Ersöz, F. (2014). Otomobil seçimine çok kriterli yaklaşım önerisi. İşletme ve İktisat Çalı̧maları Dergisi, 2(4), 110118.

Yalçın, N. ve Pehlivan, N. Y. (2019). Application of the Fuzzy CODAS method based on fuzzy envelopes for hesitant fuzzy linguistic term sets: A case study on a personnel selection problem. Symmetry, 11(4), 493.

Yıldız, A. ve Deveci, M. (2013). Bulanık VIKOR yöntemine dayalı personel seçim süreci. Ege Akademik Bakış, 13(4), 427-436.

Yu, S. M., Wang, J. ve Wang, J. Q. (2017). An interval type-2 fuzzy likelihoodbased MABAC approach and its application in selecting hotels on a tourism website. International Journal of Fuzzy Systems, 19(1), 47-61. 


\section{Kaynakça Bilgisi / Citation Information}

Ulutaş, A. (2019). Entropi ve MABAC yöntemleri ile personel seçimi. OPUS-International Journal of Society Researches, 13(19), 1552-1573. DOI: 10.26466/opus.580456 